\title{
La rebelión contra el tiempo: una metáfora de los exilios de Antonio Rodríguez Huéscar
}

\author{
Rebellion Against Time: A Metaphor for Antonio Rodríguez \\ Huéscar's many exiles
}

JOSÉ LASAGA MEDINA*

\begin{abstract}
Resumen: Se trata de reflexionar sobre la experiencia de los exilios que vivió Rodríguez Huéscar desde el final de la guerra civil. Para ello llevo a cabo el análisis de un texto redactado en 1951 sobre el paisaje de su tierra manchega, interpretado como metáfora de su vivencia ante un paisaje devastado por una guerra. Y, en paralelo, se narran las circunstancias de la vida de Huéscar que justifican el uso de la expresión "exilio interior" junto al exilio o emigración a Puerto Rico que llevó a cabo desde 1956 a 1971.

Palabras clave: Exilio interior, paisaje, Ortega y Gasset, don Quijote,
\end{abstract}

\begin{abstract}
This essay is a reflection about the many exiles that Rodríguez Huéscar lived since the end of the Spanish Civil War. This reflection is done through an analysis of one of his texts from 1951 where Huéscar writes about the Manchegan landscape which he interprets as a metaphor for his experience against a landscape devastated by a war. At the same time, I explore the circumstances in Huéscar's life that justify the use of the expression "interior exile" along with his exile or immigration to Puerto Rico that lasted from 1956-1971.
\end{abstract}

Keywords: interior exile, landscape, Ortega y Gasset, Don Quixote.

El exilio no es más que el nombre elegante de una gran derrota ${ }^{1}$

\section{Paisajes para después de una guerra}

1951 no fue un año con una significación especial en la vida de Rodríguez Huéscar. Por el contrario, las fechas que despuntan en su trayectoria biográfica en relación con los exilios o destierros o emigraciones, de que me propongo hablar, son 1938, 1956, 1971 y 1990.

1 Afirmación de un personaje de la novela Turcos en la niebla de Enrique del Risco.

Recibido: 24/07/2019. Aceptado: 18/09/2019.

* Profesor de Filosofía de la UNED. Publicaciones recientes: Hannah Arendt. Un ensayo biográfico Madrid, Eila eds., 2017. Mis líneas de investigación: Filosofía española contemporánea. jlasagam@gmail.com 
Y son estas porque marcan los hitos de sus alteraciones existenciales: 1937: herido en el frente republicano, una convalecencia prolongada le permite no reincorporarse. El final de la guerra civil le sorprende en un pequeño pueblo de Ciudad Real, Torre de Juan Abad, donde era maestro. 1955 es la del comienzo de su emigración a Puerto Rico. Debió empezar a dar clase en enero del 56. 1971, es la fecha de su regreso a España y de su incorporación como catedrático de instituto de enseñanzas medias. 1990, el año de su muerte².

1951, sin embargo, me interesa porque es el año en que redacta "Homo Montielensis. La rebelión contra al tiempo" aunque no será publicado, y fuera de España, hasta 1958 .

Aunque la guerra civil está lejos cronológicamente, algo más de una década, quizá no esté del todo ausente en la intencionalidad de su autor, aunque el asunto en principio no lo sugiere: una reflexión sobre el paisaje y el hombre que lo habita. El paisaje es su paisaje, el del Campo de Montiel, al sur de la Mancha, cerca ya de las estribaciones de Sierra Morena. El autor es consciente de que va a decir cosas intensas, duras, provocadoras y se disculpa por ello. Habla de

unas líneas desordenadas, expresión de ideas y sentimientos que me asaltaron atropelladamente, hace ya tiempo, vagando por este dramático paisaje manchego que tan profundamente amo y cuya entraña significativa tan acendradas esencias de españolidad traduce.

La lectura que me propongo hacer del ensayo sobre el hombre de Montiel se articula en tres niveles: el biográfico, el político y el metafísico. Espero mostrar que la diferencia analítica de los planos mencionados queda subsumida en una única perspectiva sintética que, a mi juicio, refleja exactamente el punto de vista desde el que fue contemplado el paisaje manchego, un día del verano de 1951, a una hora determinada que obviamente no puedo precisar: desde el extrañamiento de un exilio no solo material o político sino metafísico.

Es el paisaje de la infancia y la juventud definitivamente dañado por una guerra que destruyó no solo oportunidades vitales y esperanzas razonables, sino el ser mismo de aquel mundo al que ya nunca se podría volver, por más que uno hiciera el gesto de regresar. Acaso el verdadero desastre de una guerra no es destruir el futuro, que de alguna forma se rehace, sino el pasado, y no el pasado lejano, sino el más próximo a la circunstancia presente, el que, en condiciones normales, le sirve de suelo desde el que poder vivir. Porque el superviviente descubre pronto que el mundo para el que vivía y para el que forjó planes, ha dejado de existir.

Comenzaré por el plano biográfico: se trata del paisaje familiar de su infancia y primera adolescencia hasta que marcha a estudiar a Madrid, de donde vuelve periódicamente a la casa familiar, en Fuenllana, a pocos kilómetros de Villanueva de los Infantes. Este pueblo, donde terminó sus días Francisco de Quevedo, aparece mencionado en su escrito. El plano metafísico es la razón de ser del texto, y donde se resuelve su intención más profunda, como espero mostrar. Huéscar desarrolla una teoría del tiempo vital basado en

2 Agradezco a Eva Rodríguez Halffter la lectura del manuscrito y la precisión sobre algunas de las fechas mencionadas.

3 Primera edición en La Torre, Revista de la Universidad de Puerto Rico, año VI, n 22, abril-junio, 1958. Citamos por Rodríguez (1964, 311-336), con las siglas HM seguidas del número de página. 
la metafísica de su maestro Ortega. Merece la pena señalar que no estamos ante un mero ejercicio escolar, pues no se limita a presentar una teoría ya envasada, sino que realiza un aventurado ejercicio de especulación a medio camino entre la metafísica y la filosofía de la historia y, apurando un poco, la psicología de los pueblos. En cuanto al plano de lo político, es lo que no se declara, presencia aludida e implícita. El texto permanecerá inédito hasta que pueda ser publicado lejos del paisaje físico y humano que lo inspiró, al otro lado de un océano.

Quien escribe es alguien implicado, incluso afectado, por el paisaje, al que reacciona no solo de forma intuitiva y sensible, sino sobre todo intelectual. Quien escribe es un filósofo o espera serlo. Si, como se suele decir, el estilo revela al hombre, detengámonos un momento en las pocas líneas citadas al comienzo: el paisaje contiene una entraña, es decir una intimidad que lo es de significados, esto es, de sentidos que le corresponde al filosofo desvelar; y lo que habrá que desvelar son esencias de españolidad traducidas, es decir, trasladadas desde el particular paisaje manchego hasta un sentido general sobre el ser de España, su realidad histórica.

Reparamos en que Rodríguez Huéscar se preocupa por usar con precisión el lenguaje, con una voluntad que promete no quedarse en la superficie de las cosas. Por eso, porque ha sido siempre la tarea de la filosofía ir al fondo de las cosas, comencé por señalar que el autor del texto era o pretendía ser filósofo. Es cierto que en cada época ha sido distinta la forma en que se ha enfrentado esa tarea de desvelar lo oculto. Pero la tarea ha sido la misma desde que la emprendieron los presocráticos y que aquí retoma nuestro autor con toda humildad pero también con toda decisión.

¿Estamos ante una confesión? ¿Habla Huéscar consigo mismo sobre la mitad de su constitución vital, lo otro de su yo, un paisaje habitado? Es la mitad que no ha elegido, el lote que le ha tocado en suerte para hacer su vida, como lo fue su cuerpo, su lengua y su familia, y la fecha de su nacimiento, que determinaría que al cumplir 24 años estallaría una guerra, es decir, lo que llama Ortega "circunstancia".

Estamos pues ahora en Fuenllana, entre Montiel y Alhambra. Salgamos al campo por el lado de Montiel. Ante nosotros se extiende una amplia llanura que ondula suavemente: barbecheras sombrías, misteriosas, y rastrojos crueles ocupan toda la tierra, caprichosamente parcelada. Todo verdor ha sido abolido por la terrible solanera y la piel de la tierra parece cauterizada y en suplicio, llena de desgarraduras y pústulas. Solo tres chopos como tres esbeltas plumas, se yerguen allá lejos, entre la horizontal geometría de los predios resecos, aspirando heroicamente al verde utópico (HM, 313).

Es verano, probablemente agosto, y eso explica que el paisaje padezca bajo la "terrible solanera", pero no es difícil advertir que hay una segunda intención en la descripción. Huéscar piensa ya en el hombre que habita el paisaje y lo que es más importante, piensa en el sentido oculto de ese paisaje manchego que es parte de España. Declara la intención: ha tomado la pluma para evocar su paisaje familiar acuciado - para emplear su término - "por esa necesidad que cada español padece de desentrañarse su propia sensación de España" (HM, 311). 


\section{2. ¿Quién es Antonio Rodríguez Huéscar en 1951?}

Un profesor que enseña filosofía en un colegio privado, el colegio Estudio ${ }^{4}$, que terminó unos brillantes estudios de filosofía en la mejor Facultad de Filosofía y Letras de la historia de España, que aprobó un curso-oposición a cátedras de instituto en junio de 1936; que fue movilizado como soldado de la Segunda República, que terminó la guerra convaleciente en un hospital de Valencia de una herida en la pierna y que tardó en curar, más de las heridas del alma que de las del cuerpo ${ }^{5}$.

Después de la guerra no se le reconoció la oposición y con escasos medios de vida marchó de Madrid a Tomelloso para hacerse cargo de la dirección de un colegio de segunda enseñanza y de un montón de materias. Así las cosas, no podía retomar sus estudios de filosofía. Su ambición era iniciar un doctorado para profundizar en la filosofía de Ortega. Pero con los profesores de su facultad o muertos o exiliados, con los compañeros, aislados unos de otros, era prácticamente imposible pensar en reanudar estudios. Por otro lado estaban las necesidades familiares. Antonio estaba casado y tenía una hija, Elena. Conocemos algunos detalles de la cotidianidad de Antonio y su familia en los cuarenta por una carta que dirigió a Ortega cuando le llegó la noticia de su regreso a Europa y su instalación en Lisboa:

Creo que esta es la primera vez que acudo a Vd. en actitud casi de suplicante; por lo menos, en actitud de desnuda angustia, presentándole abierta mi intimidad personal. (...) Han transcurrido años preñados de acontecimientos que han modificado profundamente la posición en el mundo, la vida de cada cual. Y después de todo esto sería ridículo que yo intentase ahora reanudar una de aquellas conversaciones de "discípulo". (...)

Si quisiera expresarle con una sola palabra el precipitado vital que han dejado en mí estos años azarosos y terribles, creo que la más adecuada sería ésta: descenso. Así es como siento este trozo de mi vida: como un descenso o una depresión. Estos años no han tenido para mí ninguna fecundidad; los siento tan estériles que propendo siempre a pensarlos bajo la imagen de un paréntesis - paréntesis que todavía no se ha cerrado- , imagen que comprendo que no puede ser exacta. (...) Mi temple, que no debe ser muy

4 "El Colegio Estudio quiso ser y fue en efecto, en el Madrid de la posguerra continuador de las tradiciones educativas de la Institución Libre de Enseñanza. (...) A comienzos de 1940, tres mujeres, Jimena Menéndez Pidal, Ángeles Gasset - sobrina de Ortega - y Carmen García del Diestro, pusieron en pie, al principio con dimensiones modestísimas, el Colegio Estudio. La misma modestia del proyecto hizo que durante bastante tiempo pasara desapercibido.

(...) Estudio fue de hecho durante muchos años un islote de liberalismo, al que un número cada vez mayor de intelectuales y familias cultas de clase media enviaban a sus hijos, y al que en muchos casos proporcionaban también profesores. Muchos y muy destacados dirigentes estudiantiles de los años 50 y 60 pasaron por sus aulas. No es extraño pues que durante los altercados estudiantiles de febrero de 1956 el Colegio Estudio fuera saqueado por un grupo de falangistas" (Padilla, 2004: 41).

5 Un testimonio indirecto de la convalecencia de Antonio en la entrevista con A Mindán (2001: 68). Evocando el regreso de José Gaos a España cuando hubo terminado su misión como director del Pabellón de España en la Exposición internacional de París, escribe: "Volvió a España desilusionado sobre la suerte de la guerra. Su pesimismo sobre la guerra se hizo definitivo en una conversación que tuvo en Valencia con el amigo Antonio Rodríguez Huéscar. Este había sido herido en el frente republicano y fue a convalecer a Valencia. En la visita a Gaos le transmitió su convicción de que la guerra estaba perdida; le aseguró que en los frentes no había moral de lucha, ni siquiera de resistencia”. Esta conversación, precisa Mindán, tuvo lugar en la primavera de 1938. 
fuerte, acusa el clima de violencia, invariablemente, como un aire catastrófico y letal; en él siento que se paralizan todos los resortes de mi actividad. No sé hasta qué punto soy responsable, culpable, de esta incapacidad de reacción vigorosa. Muchas veces percibo, en efecto, la mordedura de esta culpabilidad (...) Durante nuestra guerra, mi suerte no puedo decir que fuera muy mala, puesto que vivo, y esto de vivir, era por entonces máxima aspiración de las gentes. Sin embargo, durante aquellos tres años viví casi exclusivamente bajo las sensaciones de un animal perseguido (...) En fin, hube de pasar por miserias, sobresaltos y conmociones que dejaron mis nervios maltrechos. Yo no fui de los afortunados que encontraron una embajada acogedora o una "protección" oficial o extraoficial en que escudarse y a cuya sombra seguir más o menos tranquilamente sus actividades, sino que tuve que hacer frente al vendaval atenido exclusivamente a mí mismo (...).

Después de la guerra me encontré frente a la necesidad de ganarme la vida - una vida de día en día más encarecida - dando clases; y esto es lo que he hecho y sigo haciendo. Pero este trabajo es enojoso y no deja suficiente tiempo libre para hacer otras cosas; además, la vida es áspera y difícil; de modo que no he hecho nada de provecho en todo este tiempo. En realidad, mi crisis nerviosa no ha pasado todavía, aunque voy logrando reponerme poco a poco (...). Además, las pequeñas ventajas materiales conseguidas sobre Madrid son demasiado caras, pues valen el precio de una soledad de desierto. Esta soledad, esta falta de aire intelectual, son aquí absolutos y asfixiantes. Por lo demás, tampoco en otros sitios -incluso en Madrid - ocurre algo muy diferente (...).

¿Ha tenido la culpa la guerra de esta especie de derrumbamiento de nuestra generación? Esto Vd. lo sabrá mucho mejor que yo. Quizá no pueda hablarse todavía de derrumbamiento, quizá no ha ocurrido todavía nada definitivo, pero indudablemente aquí ha fallado algo, se ha roto algo fundamental. Esa es, por lo menos, mi impresión ${ }^{6}$.

El lector apreciará que el interés de la cita justifica su extensión. En efecto, pocas veces es posible concretar una fórmula abstracta, como todas las que remiten a experiencias de vida, en sus contenidos más reales y auténticos. Ahora es posible hacerse una idea de qué puede significar la expresión "exilio interior", si no como experiencia universal, sí en el caso de la generación de los que perdieron la guerra y se quedaron en España. Inseguridad, interinidad, auto-desprecio y mala conciencia, vacío existencial, aislamiento, más que soledad, resentimiento, impresión de fracaso... Pero está el hecho mismo de la carta y de que esta fuera enviada; es decir, está la voluntad de hacer algo para poner fin a la situación de frustración e indefensión. Como observa Eva Rodríguez Halffter, el tono de la carta es de firmeza, y hasta conminatorio...7. Ello solo puede significar que Antonio se dispone a dar la batalla a pesar de la inhospitalidad del panorama que tiene ante sí.

6 La carta fue editada por mí y José E. Esteban en el monográfico “Antonio Rodríguez Huéscar: una vocación filosófica" (Esteban, Lasaga, 2015: 26-36). En rigor se trata de tres cartas: una primera, de donde hemos tomado las citas, sin fecha, aunque con toda probabilidad remitida en la primavera de 1942; la respuesta de Ortega a Huéscar fechada en Lisboa, 21 de marzo, 1943; y una segunda de Antonio a Ortega desde Tomelloso, 24 de abril 1943. Véase para más detalles la introducción.

7 "Pero a mí me sorprende el tono (...) que es a veces hasta conminatorio. Y modifica en cierto modo mi imagen de mi padre con respecto a Ortega. Antonio, en principio, se dirige a Ortega como «un áncora de salvación», 
En efecto, no era fácil ser orteguiano en la posguerra franquista ${ }^{8}$. Podríamos evocar el hecho de que a Julián Marías se le suspendiera una tesis de doctorado, sobre un clérigo francés, el Padre Gratry, dirigida por Xavier Zubiri para hacernos una idea de cómo estaban las cosas. Pero Ortega estaba ahí, gravitando con su prestigio relativamente intacto. Las contadas ocasiones en que Ortega hizo acto de presencia en público fueron ninguneadas por la prensa. No debe engañarnos el hecho de que, durante algún tiempo, antes de que perdieran el poder cultural que detentaban los llamados "falangistas liberales", Ortega, Unamuno, y hasta Antonio Machado fueran autores leídos y citados ${ }^{9}$. El fondo del asunto estaba, sin embargo, en la inequívoca superioridad intelectual de la filosofía de la razón vital sobre las entelequias neo-escolásticas que habían tenido que recuperar apresuradamente los nuevos usufructuarios de las cátedras detentadas gracias a su condición de vencedores de una guerra. Esto era tan evidente que hubo que inventarse un fantasma, el de una supuesta "escolástica orteguiana", a la que había que cerrarle el paso.

Cuando ya no pudo impedirlo porque estaba muerto, se celebró en su Facultad de Filosofía y Letras un acto de homenaje a la memoria del que había sido su catedrático de metafísica desde 1910. Con la salvedad de alguna intervención como la de Gregorio Marañón, lo verdaderamente significativo del acto fue el intento, hasta cierto punto exitoso en aquella universidad, de declarar amortizada la filosofía de Ortega. Lo expresó claramente Ángel González Álvarez (1955: 28), que a la sazón ocupaba la mencionada cátedra, en su discurso:

Se cierra el ciclo de la modernidad, que en el pensamiento de Ortega encuentra la justa revelación teórica de los supuestos vitales que la hicieron posible como tarea. Así reconocida en su fundamental significación, la filosofía orteguiana se nos muestra hermética al ser y sin posibilidad de elaborar una ontología (...) La filosofía europea que en la actualidad se está gestando se libera ya de la modernidad y nos ofrece un futuro prometedor en el retorno a la metafísica (...) Estoy firmemente convencido de que una escolástica orteguiana destruiría lo mejor de Ortega, privaría a España de la incitación al futuro y la agostaría en un pretérito superado (énfasis añadido).

que no es poco. Pero también le dice «quiero salirme de mi papel de discípulo» y dirigirme a él como «hombre concreto»..." (Rodríguez, 2015: 38).

8 Santos Juliá (2004: 355) recuerda que a comienzos de la década de los 50 había cierta unanimidad sobre el hecho de que en España "todos los intelectuales eran católicos" y atribuye dicho acuerdo a Rafael Calvo Serer y a Aranguren. Este tomaba nota del cambio de clima que se había producido en España a raíz de la guerra civil. Las generaciones anteriores "habían creado obras admirables sin tomar en cuenta para nada a Dios", a partir de la República las cosas cambiaron radicalmente. "Durante un cuarto de siglo España había asistido a una verdadera 'primavera católica'. Prácticamente todos los escritores de su generación que se quedaron aquí después de la guerra, pero también muchos de los que se fueron 'hemos sido católicos"'. La pregunta elemental es: ¿Qué espacio público podía quedar para aquellos que, orteguianos o no, no se sentían identificados con los ideales católicos? La respuesta es: ninguno. Huéscar podía escribir sus reflexiones sobre el hombre de Montiel pero no iba a tener donde publicar, al menos no aún por varios años.

9 Aunque el tono era "prudente": Así se refería a la posible recuperación de Ortega uno de sus grandes adalides, Pedro Laín, (1955: 74) que deseaba "una España en que, bajo la suprema y consoladora verdad en Cristo (...) convivan de manera eficaz y amistosa el pensamiento de St. Tomás y el pensamiento de Ortega...”. 
En su aislamiento manchego, Huéscar creía que era responsabilidad de su generación el haber fracasado. Al regresar a Madrid comprobó que todo estaba diseñado para que la parte de su generación que se encontró en el lado equivocado de la historia fracasara.

La universidad y con ella todo el sistema de centros de investigación, editoriales y revistas estaba cerrado a los orteguianos que, como Huéscar, no tuvieron ninguno de los dos salvoconductos que podían aminorar o evitar la condición de paria: el falangista o el católico. Laín o Aranguren tuvieron ambos. Marías, aun manteniendo en todo momento una decorosa distancia con el Régimen, estaba integrado en los circuitos culturales del catolicismo. Con la distancia puede parecer increíble que la gran cuestión de aquellos quince años que van del inicio de la posguerra a la muerte de Ortega (1940-1955) fuera la neutralización de la "escolástica orteguiana". "Por más que cueste creerlo, el tema principal del debate intelectual de la segunda mitad de los 50 — resume Santos Juliá (2004: 387) - fue si Ortega había sido una agencia de fabricar ateos". Autores como Aranguren con su Ética de Ortega o Antonio Maravall con su opúsculo "Ortega en nuestra situación" argumentaban que las ideas de Ortega no solo eran compatibles con las verdades cristinas, sino que "no conozco un solo caso de apostasía — argumentaba Maravall (1959: 14) - ni provocado ni relacionado con la influencia de Ortega".

Huéscar no disponía de avales y había decidido no buscarlos. Pero afortunadamente recuperó su temple. Su regreso a Madrid, el empleo en un centro como el Colegio Estudio, la aparición de algunas oportunidades como la dirección de la colección de clásicos de historia de la filosofía, aquellos libritos de portada verdosa que editaba Aguilar, precedido el texto del clásico por un ajustado prólogo de Huéscar ${ }^{10}$. También estaba la proximidad del maestro, que pasaba largas temporadas en Madrid.

Disponemos de un retrato del profesor de filosofía del colegio Estudio, debido a Javier Muguerza (2004: 12):

Era un profesor sobrio y poco dado a apostolados ni proselitismos, con conciencia sin duda del absurdo de "enseñar filosofía" y un tanto escéptico acerca de la buena disposición de sus estudiantes para 'aprender a filosofar'. En consecuencia, se limitaba a mostrar honestamente lo que era para él el 'ejercicio' de la filosofía y, a partir de ahí, dejaba en absoluta libertad a su auditorio. Pero dado que ni lo uno ni lo otro era demasiado común en la enseñanza de la filosofía en aquellos años, el impacto de una actitud como la de Rodríguez Huéscar podía llegar a ser muy grande ${ }^{11}$.

A comienzos de los cincuenta, Huéscar comenzó a recibir invitaciones para trabajar en universidades americanas, pero tomó la decisión de no irse de España mientras Ortega viviera. Y, en efecto, un año después de su fallecimiento en octubre de 1955, acepta la solicitud de una de las mejores universidades de habla española, fundada además por un discípulo de Ortega, Jaime Benítez, la Universidad de Puerto Rico en Río Piedras, donde por cierto se encontraban ya impartiendo docencia otros españoles como Manuel García-Pelayo, futuro presidente del

10 Él mismo reunió dichos prólogos en un volumen titulado Del amor platónico a la libertad que ha sido reeditado recientemente en Madrid, Biblioteca Nueva, 2009.

11 El propio Muguerza atribuye a Huéscar el haber sido atrapado por la vocación filosófica. Valga este recordatorio como recuerdo y homenaje ante su reciente fallecimiento. 
primer Tribunal Constitucional de la nueva democracia, Francisco Ayala, Rodríguez Bachiller, un matemático buen amigo suyo o el poeta Juan Ramón Jiménez, que recibiría el premio Nobel residiendo ya en Puerto Rico, el mismo año de la llegada de Antonio.

\section{Lo subyacente en aquel paisaje}

Prestemos atención a lo que sugiere el paisaje montielense a su espectador. Primero, las metáforas visuales: "barbechas sombrías", "rastrojos crueles", "verdor abolido por la terrible solanera". Las metáforas parecen ordenarse en torno a la imagen de un cuerpo, si no torturado, sí lacerado y doliente: piel de la tierra cauterizada y en suplicio llena de desgarraduras y pústulas. Y cuando salimos al inmenso valle de Montiel lo que podemos ver sobre una colina es "la bárbara mutilación de lo que fue su castillo", unos pedruscos grisáceos, unos restos carcomidos de muro izados en lo alto de empinadísimo cerro. Aunque al fondo, como una aparición, el verde intenso de unos chopos que rompen con la lógica del paisaje.

La impresión que a mí me transmite esta cadena de imágenes es la de estar ante el paisaje después de una batalla.

Pero lo que le interesa a Huéscar no es la materia del paisaje sino su espíritu y eso implica a los hombres que lo habitan y lo construyen. Porque es evidente: no hablamos de un paisaje natural, virgen, sino de uno con mucha historia. Y lo que ve Antonio detrás de la tierra, de la sequedad, de la aridez es "el aire que tiene todo de haberse detenido la vida"; los hombres y mujeres que pasan por sus caminos y habitan sus pueblos son tipos humanos "con una cantidad de raza que estremece". La expresión resulta extraña y difícil de entender. Poco más abajo aclara lo que quiere decir:

En el fondo de esta raza de hombres hay un tamo turbio de disposiciones vivenciales, producto de la decantación secular de muchos pretéritos. Es, por excelencia, el pretérito indefinido, lo 'antiguo', lo inmemorial, casi lo legendario, el elemento en que hunden sus misteriosas raíces, estas vivas figuras de retablo (HM, 315).

Y llegamos, conducidos por esta afirmación, al plano metafísico del texto que por lo demás, Huéscar declara con precisión en el subtítulo: la rebelión contra el tiempo.

A primera vista tenemos que seguir extrañados. ¿Quién puede rebelarse contra el tiempo? ¿Acaso no está en la textura más íntima de nuestra vida? Es más, ¿no descubre Ortega que la realidad radical y última de las cosas depende de que aparezcan en nuestra vida?, ¿y no es la temporalidad lo más constituyente de ella? En algún sitio ha dicho Ortega que la fecha de nacimiento es media biografía de la persona. Huéscar no lo ignora. Pero precisamente porque sabe bien que la vida humana tiene en su entraña una estructura y una dinámica temporales, es por lo que, al ver a esos paisanos suyos del Campo de Montiel viviendo como figuras cuasi legendarias de un retablo anclado en el pasado, no puede por menos que extrañarse y, como él mismo explica en otro texto ${ }^{12}$, en el extrañamiento está el origen de la filosofía.

12 "Sobre el origen de la actitud teorética" (Rodríguez Huéscar: 1964). El autor fecha el trabajo en 1939 aunque no aparece publicado en la Revista Theoria (Madrid) hasta 1952. Es junto con "Aspectos del magisterio orteguiano" (1953) y el ensayo que nos ocupa, lo único que escribe Huéscar en este primer exilio interior. 
La vida humana en su tensión dinámica hace que el presente, en el que cada uno de nosotros vivimos y estamos, sea no más que una tensión entre el pasado y el futuro, una fina arista en la que se cortan las dos dimensiones temporales que conforman la realidad de nuestra vida. Es más, el humano es el único viviente que experimenta el tiempo en sus tres dimensiones articuladas. El animal habita un presente circular ordenado por el ciclo de la necesidad. Por eso ha podido decir Milan Kundera que el animal no ha abandonado el paraíso: porque ignora el tiempo: apenas tiene pasado pero, sobre todo, carece de futuro y eso puede que se parezca a la eternidad ${ }^{13}$. El pasado es el ya-no y el futuro el todavía-no. Ambos son simultáneamente "irreales" pero lo que da su profundidad al presente actual. La vida es un perpetuo ir del pasado al futuro, del nacimiento a la muerte; sin marcha atrás: vivir es hacer cosas a partir de lo que somos y tenemos, en vista de lo que necesitamos, deseamos, queremos o aspiramos. Esto lo resume Ortega diciendo que la vida humana es proyecto y futurición. De ahí el asombro de Huéscar: "Imagínese entonces la extraña condición de una vida que intenta sustituir esta proyección hacia el futuro por una retro-yección hacia el pretérito" (HM, 316). Y a continuación saca las consecuencias de este absurdo, porque el sentido temporal de la vida

...queda así dislocado, invertido; se convierte en un repetir, en un perpetuar lo ya sido - gestos, acciones, actitudes, creencias - , en un tenaz permanecer adscrito a formas o fórmulas, a normas y usos inveterados, arcaicos; en fin, se torna un instalarse en el ámbito espiritual de los fantasmas, de los revenants (HM, 314).

De este análisis cuelgo mi lectura política del texto. ¿Pues no había sido el propósito de la dictadura legitimarse hablando de las grandezas del pasado después de 1945, cuando las fuerzas del Eje fueron derrotadas? ¿No se puso en marcha la operación de congelar el tiempo, de dislocar su estructura temporal? Pedro Laín Entralgo aún había escrito un libro titulado España como problema, lleno de citas de Ortega, de Unamuno, incluso de Antonio Machado. A lo que contestó Calvo Serer con otro titulado: España sin problema. ¿La solución? Traer al presente las glorias pasadas. Había que vivir en filosofía de Tomás de Aquino y de Suárez, es decir, de una filosofía que se llamó a sí misma - con orgullo - philosophia perennis. Habían refutado a Kant, a Hegel y no digamos a Marx. A Ortega lo había impugnado Menéndez Pelayo antes incluso de que comenzara a escribir Meditaciones del Quijote (1914). Y la mitología para consumo popular iba, como es sabido, de los Reyes Católicos y el Gran Capitán a Agustina de Aragón y, por supuesto, Santiago y cierra España. En efecto, cerrar España había sido el sueño del dictador. Ortega había diagnosticado el síndrome de decadencia en la España de los Austrias hablando de tibetanización, de una especie de aislamiento del resto del mundo que entonces había sobrevenido. Huéscar se sirve de la metáfora para aplicarla a su presente: segunda tibetanización entrevista en el paisaje del Campo de Montiel. El texto se puede leer como una alegoría del español que experimenta su exilio interior, en 1951, condenado a la alucinación o a la melancolía.

13 Aunque sea de pasada, observemos que Heidegger fue impreciso al deslindar la vida humana de la animal. El animal no es pobre en mundo (dimensión espacial de nuestra vida) sino pobre en tiempo, especialmente en la dimensión del tiempo que atañe a la libertad, el futuro. 
Pero regresemos a lo que importaba a Huéscar, que no era sino el problema humano, histórico, metafísico de aquella forma de vida. No ignoraba una objeción obvia: ¿acaso no había llegado al Campo de Montiel la aspirina y el motor de explosión, es decir, no se habían hecho allí realidad los avances de la civilización técnico-industrial? La respuesta es que sí, pero que eso operaría en un plano de la existencia más bien superficial, que no afectaría a las zonas profundas del alma, descrita por Antonio como "alma hermética e inerte", propicia a la alucinación que surge cuando la realidad es rechaza y negada, sustituida por el imposible de habitar en un pasado destruido precisamente por el trabajo del tiempo.

De la Mancha hablamos y eso significa que no puede estar lejos don Quijote, el gran alucinado.

Huéscar vincula el alma del hombre de Montiel con el alma quijotesca. El análisis del alma de don Quijote es quizá la parte más ambiciosa e interesante del texto. Nuestro autor reconoce en toda su amplitud la complejidad del problema. Por de pronto, hace una primera distinción: hablamos de don Quijote, el personaje, no de la novela, es decir, no de la perspectiva de Cervantes sobre su personaje; segunda: se trata de admitir en el alma de don Quijote dos dimensiones: la del alucinado incapaz de tocar la realidad que Huéscar interpreta como resultado de un alma inercial. Chocará esta descripción, opuesta a la usual interpretación romántico-idealista (y unamuniana) que juzga al Caballero por su esfuerzo, alma perpetuamente excitada por una voluntad que no se conforma con lo real en afirmación de un ideal. Pero atendamos al matiz: don Quijote va embalado por la inercia de su propio ensueño, incapaz de corregir la trayectoria, es decir, incapaz de interpretar los desafíos que la vida le impone. No se discute que se esfuerce y luche, pero siempre en el sueño. El efecto cómico de la novela reside precisamente en que don Quijote hace todo lo posible para defenderse de lo real, no importa lo violento y enérgico que se muestre ni el ridículo en que incurra. De ahí su conclusión anti-romántica: "Don Quijote es solamente el sueño de un héroe albergado en el cerebro de un loco" (HM, 323).

Esto no es incompatible con la intensa admiración que despierta don Quijote y que Huéscar no le regatea: "La gracia y la grandeza están en ese empeño trágico y honroso de imponer a la brutal realidad un canon de perfección ideal” (HM, 324). Pero es su voluntad lo heroico, no su razón enajenada. Y por eso está condenada a reconocer, cuando finalmente la terca realidad lo obliga a sanar, que es poca cosa lo que consigue con sus esfuerzos. El propio caballero parece darse cuenta cuando exclama: "Y yo hasta agora no sé lo que conquisto a fuerza de mis trabajos"14.

Huéscar prueba la coincidencia entre un rasgo decisivo del alma del hombre montielense y don Quijote, el de su insania, el de su existencia alucinada. Pero, ¿qué pasa con la otra esencia la digna de admiración de don Quijote, su voluntad, su esfuerzo por aproximar este

14 La afirmación de don Quijote, tantas veces citada, anuncia la transformación del ímpetu de hazañas en melancolía realista, aunque Cervantes, en su infinita inteligencia, hará que esta le llegue poco a poco. Don Quijote acaba de encontrarse con unos labradores que llevan unos bultos cubiertos. La curiosidad del caballero le lleva a preguntar qué hay debajo de las sábanas. Y comprueba que son estatuas de santos. El Caballero manda que las vuelvan a cubrir y comenta: "Por buen agüero he tenido hermanos, haber visto lo que he visto, porque estos santos y caballeros profesaron lo que yo profeso, que es el ejercicio de las armas; sino que la diferencia que hay entre mí y ellos es que ellos fueron santos y pelearon a lo divino, y yo soy pecador y peleo a lo humano. Ellos conquistaron el cielo a fuerza de brazos, porque el cielo padece fuerza, y yo hasta agora no sé lo que conquisto a fuerza de mis trabajos..." (Segunda parte, cap. 58). 
mundo a su mundo de ideales? También la va a encontrar, escondida donde menos puede esperarse. Con una lógica que no admite réplica, afirma en relación al objeto de la voluntad: "ser menos vida quiere decir ser más muerte".

Para entender el insólito giro que Huéscar da a su argumento notemos que su interpretación del héroe quijotesco tiene presente la superación o corrección de la figura moral del "héroe", que Ortega lleva a cabo entre su primera lectura como héroe de la voluntad ${ }^{15}$ y la segunda en el prólogo "Lector" de la misma obra, redactado dos años después, en donde aparece un héroe próximo a la circunstancia, que ha de evitar la obsesión romántica que solo presta atención a "remotas empresas", proyectada la voluntad "hacia la conquista de lejanas ciudades esquemáticas” (I, 754). Huéscar critica a don Quijote desde una concepción del ideal absolutamente no utópica, no idealista.

Pero tampoco está trabajando aquí el ser-para-la muerte de Heidegger, esa otra negación del idealismo. La razón vital de Ortega había vacunado a sus discípulos contra lo que otro de ellos, buen amigo de Antonio, José Gaos, llamaba con expresión mexicana "metafísica de velorio". Huéscar reflexiona sobre lo que mueve al montielense a despreciar la vida y descubre que la razón es precisamente, que sea temporal, que sea escasa y pobre, que se termine pronto. Aspira nada menos a que la vida sea eterna y parece no conformarse con menos. De ahí la rebelión contra el tiempo, única forma de afirmar la eternidad en la vida corporal y finita. Entramos de lleno en el terreno de la paradoja y Antonio recurre al gran maestro español de las paradojas, Unamuno, que no pensaba en realidad de manera distinta a como lo hacía el hombre de Montiel. Huéscar asocia la actitud del hombre de Montiel con el tema barroco de la vida es sueño. De Calderón a Unamuno, la experiencia del paso del tiempo se vive como irrealidad: "aspira a que el tiempo pase ante ella, sin que ella misma deba, por eso, pasar" (HM, 331). Pero solo cuando se niega el presente, condenado a pasar, y se sueña en un presente continuo, es posible aliviarse en la ficción de la eternidad. Al precio de no vivir, de ignorar el imperativo de salvar la circunstancia. Y aún es posible que Huéscar esté pensando, no ya en el perfil del hombre del sur de la Mancha, sino del español en general y del español en una fecha determinada del siglo XX. En un momento dado, el sujeto de la reflexión no es el usual "hombre de Montiel": "Tocamos con este tema - la actitud del hombre ibérico frente al tiempo - algo donde late uno de los más graves y profundos secretos del alma española” (HM, 331). ¿Qué vínculos, igual de secretos, podía haber entre ese fondo ibérico del alma española y la experiencia relativamente reciente de aquella guerra civil que no terminaba de pasar?

¿Qué significa una vida que quiere ser muerte, que siendo en su entraña tiempo se rebela contra el tiempo? Unamuno sabía que la vida humana solo tiene una dirección: "Como siempre se marcha al porvenir; el que anda, a él va, aunque marche de espaldas"16. Una-

15 En la "Meditación preliminar en el parágrafo titulado precisamente "El héroe" afirma Ortega (2004: I, 816): “Cómo hay modo de que lo que no es - el proyecto de una aventura - gobierne y componga la dura realidad? Tal vez no lo haya, pero es un hecho que existen hombres decididos a no contentarse con la realidad. Aspiran los tales a que las cosas lleven un curso distinto: se niegan a repetir los gestos que la costumbre, la tradición y, en resumen, los instintos biológicos les fuerzan a hacer. Estos hombres llamamos héroes. Porque ser héroe consiste en ser uno, uno mismo".

16 Citado por Huéscar (HM, 329). La cita completa reza: “Toda supuesta restauración del pasado es hacer porvenir, y si el pasado ese es un ensueño, algo mal conocido..., mejor que mejor. Como siempre, se marcha al porvenir...". 
muno comparte con el hombre de Montiel un cierto apetito de eternidad. Ese es el aspecto ideal y heroico de una existencia, sin embargo ciega para una dimensión constituyente de la realidad humana: la dimensión de la expectativa. Huéscar describe la vivencia de lo presente en el hombre de Montiel como "el pasado indefinido de lo que siempre fue o bien el futuro perfecto de la supervivencia ultramundana" (HM, 332).

Si lo comparamos con otra vivencia del presente, por ejemplo, la que escenifica Samuel Beckett en su famosa obra Esperando a Godot, advertimos que hay aquí también una especie de negación de la dinámica temporal, de la vida vaciada de futuro. La conversación interminable entre Vladimiro y Estragón va y viene sin llegar a ninguna parte. Es como si caminaran sobre una cinta móvil que se deslizara en sentido contrario al de sus pasos, de modo que siempre están en el mismo lugar, como ocurre en la representación. Por más que lo intentan no se pueden alejar del árbol muerto. Estamos ante una metáfora del nihilismo moderno. Nada tiene sentido, nada tiene valor. Sabemos que Godot, el dueño de los nombres de las cosas, no llegará. Pero no es el caso del hombre de Montiel, que no espera a nadie; por el contrario, sabe adónde va y lo que quiere. Solo que lo que quiere es imposible: la eternidad, la quietud. Y entonces la vida se le convierte en una larga serie de negaciones y silencios. El hombre de Montiel se vuelve místico.

El ensayo termina como empezó, sintiendo en palabras su paisaje:

Tempo lentísimo el de este paisaje del Campo de Montiel, como el de la vida de sus habitadores. Las agrias lomas calvas, cauterizadas; las glebas pardas, bermejas o cárdenas, tendiéndose apenas ondulantes, hasta remotas lejanías; los desiertos abertales; el reposo ensordecido de la unánime paramera, donde la soledad se cuaja en angustia de tierra pura; todo habla aquí con la voz del sueño, de la ausencia y de la muerte (HM, 335).

Pero no fue solo negación de este mundo lo que Huéscar entrevió ante el Campo de Montiel. Quizá el texto admita otra lectura. Quizá pueda ser interpretado como un metafórico conjuro contra aquel paisaje de posguerra. Por eso prefirió dejar colgando del gancho de una interrogación una esperanza: ¿de qué no será capaz este hombre de Montiel cuando despierte de su ensueño? (HM, 336).

\section{Emigración ${ }^{17}$}

Como dije, en 1956 Antonio se decide a probar suerte, como tantos españoles, antes y después de la guerra, en América. El destino elegido es la Universidad de Puerto Rico, en

(Unamuno, 2005: 504). La presencia de Unamuno en la parte final del texto es muy notable, hasta el punto de que puede afirmarse que la filosofía del "hombre de Montiel" y la del Unamuno que rechaza frontalmente la modernidad es una y la misma. Aunque Huéscar no la juzga, es evidente que considera necesario despertar. Ahora el sueño barroco del XVII se ha convertido en la modorra que la dictadura favorece en el español medio.

17 A mi juicio, Huéscar no se fue a Puerto Rico por razones políticas, independientemente de lo que pensara del régimen franquista y de la cultura nacional-católica, que había decretado la negación de cualquier cosa que sonara a "orteguismo". No hay gran diferencia entre los términos "exilio" o "emigración" porque ambos consisten en que pierdes por una violencia exterior, sea política, económica o cultural, la oportunidad de ejecutar tu proyecto de vida en el lugar, en la tierra que habías elegido — o aceptado cordialmente. La diferencia es más bien de vivencia interior, salvo que lo político sea determinante, en cuyo caso, "exilio" viene a coincidir con "destierro". 
Río Piedras, fundada en 1942 sobre planta orteguiana por Jaime Benítez. Eso quiere decir que se prestaba especial atención a las Humanidades y se cuidaba la formación de especialistas - abogados, ingenieros, etc. - en materias ajenas a su campo como la filosofía o la historia, evitando así la figura del hombre-masa que Ortega identificó como "el especialista". Huéscar impartió docencia en dicha Facultad de Humanidades. Entre sus cursos podemos citar "Las dimensiones ético-metafísicas del problema de la verdad", "Los modos de acceso a la realidad, "Tiempo y posibilidad", "Ficción y realidad", entre otros. Es fácil detectar la orientación que Huéscar imprimió a su docencia, en correspondencia con el sesgo que dio a su investigación y profundización en la teoría de la razón vital: la dimensión de lo real, es decir, la metafísica - entendida como filosofía primera - de la vida humana. La primera aproximación al núcleo de la metafísica orteguiana fue su tesis doctoral sobre El problema de la verdad en Ortega defendida en 1961 y dirigida por José Luis López Aranguren. Apareció publicada en 1966 con el título Perspectiva y verdad (Madrid: Revista de Occidente). Gaos $(1999,399)$, en una carta sin fecha, de 1969, acusa recibo del libro en los siguientes términos:

De Perspectiva y verdad le diré ahora una sola cosa de las muchas que me ha hecho pensar, pero que resume estas en un juicio de valor. La satisfacción que habría sentido nuestro común maestro al encontrar respondido de tal forma (...) aquella pregunta suya de si nos damos sus discípulos cuenta de todo lo que había entrañado en su razón vital ${ }^{18}$.

Los quehaceres propios de la docencia e investigación se combinaban con las funciones de secretario de redacción de La Torre, una de las mejores revistas de filosofía en lengua española de los cincuenta y sesenta. Estaban también las tertulias de los residentes como Juan Ramón Jiménez, Federico de Onís, Manuel García Pelayo, a los que se sumaban las visitas frecuentes y periódicas de José Gaos, David García-Bacca, Manuel Granell, Julián Marías, Pedro Salinas, Jorge Guillén y otros.

\section{Segundo exilio interior}

Huéscar decidió regresar en 1971. Mientras tanto se habían suavizado las formas de la dictadura, existía una cierta sociedad civil que podía hacer vida al margen de las instituciones. Juan Pablo Fusi (2017, passim) ha descrito en su Espacios de libertad los dos momentos en que se articuló la cultura española, primero bajo vigilancia de las instituciones franquistas y luego al margen de ellas y aun contra ellas, desde finales de los sesenta y principios de los setenta.

Un gesto de normalización fue el reconocimiento del curso-oposición que Huéscar aprobara en 1936 y su ingreso en el cuerpo de catedráticos de Instituto de Enseñanza Media, lo que decidiría el principal de su actividad como profesor de filosofía hasta su jubilación.

18 Para apreciar el elogio conviene recordar que Gaos se refiere a una queja que Ortega $(2004: \mathrm{V}, 128)$ formulara a sus discípulos, observando que no se enteraban de todo lo que contiene su proyecto de razón vital: “ ¿Ha habido alguien que haya intentado, no ya extraer las consecuencias más inmediatas de esa frase, sino simplemente entender su significación? Se ha hablado siempre, no obstante mis protestas, de mi vitalismo; pero nadie ha intentado pensar juntas — como en esa fórmula se propone- las expresiones «razón» y «vital». Nadie, en suma, ha hablado de mi «racio-vitalismo». Y aun ahora, después de subrayarlo, ¿cuántos podrán entenderlo entender la Crítica de la razón vital que en ese libro [El tema de nuestro tiempo] se anuncia?". 
Si cabe hablar de segundo exilio, aunque la España a la que regresó era muy otra que la que dejó en 1956, es porque su destino habría sido el de acceder a alguna institución universitaria o de investigación, o haber tenido expedito el campo para publicar en revistas y editoriales y recibir invitaciones a seminarios y congresos. Pero el orteguismo siguió siendo ajeno a la universidad, aunque ahora por otras razones, con otros sujetos, aunque con los mismos argumentos: Ortega no era filósofo; se quedaba en literato con ideas ${ }^{19}$. Y Huéscar siguió cantando su canción con lealtad inconmovible. En un país en el que el más tonto se cree capaz de ser ministro, Huéscar tuvo el atrevimiento de declararse discípulo y aspirar a estudiar y esclarecer la obra de su maestro. Naturalmente su gesto fue ignorado cuando no despreciado. Prueba fehaciente de lo que digo es que tuvo muchas dificultades para publicar. Desde su vuelta, solo publicó un libro, La innovación metafísica de Ortega porque ganó un concurso convocado por el Ministerio de Educación para conmemorar el centenario del nacimiento de su maestro.

Con motivo de dicho centenario en 1983 hubo cierta actividad más social que intelectual en torno a Ortega. Me refiero a que se creó la Fundación José Ortega y Gasset gracias al empeño de doña Soledad, la hija del filósofo, y a la generosidad del gobierno socialista de Felipe González. Mi impresión es que aquella efeméride no cambió nada esencial en cuanto a la situación de Ortega en el horizonte de la filosofía en lengua española. Así lo percibió Huéscar que dejó constancia en varios artículos redactados aquellos años, cuyos títulos son suficientemente significativos: "Ortega clásico prematuro" o "Presencia y latencia de Ortega". Lo que venía a constatar Huéscar es que la recepción anómala de una filosofía tan relevante, $\tan$ a la "altura de los tiempos", seguía sin corregirse. Sí, se hacía de Ortega "un clásico", pero a condición de no tener que leerlo. Al fin y al cabo se le entendía todo ${ }^{20}$.

Tenía dos libros listos para publicar para los que no halló editor y que aparecerían póstumamente, Semblanza de Ortega y Ethos y $\operatorname{logos}^{21}$. El primero recogía todos los artículos que había dedicado a glosar la figura y la filosofía de su maestro; el segundo contenía su obra más ambiciosa y original, ya que trascendía los límites de la razón vital, ofreciendo una solución distinta al problema de la verdad.

En el momento en que le sorprende la muerte preparaba un curso de verano en El Escorial con Ferrater Mora sobre un tema que les había interesado mucho a ambos: las relaciones entre filosofía y novela ${ }^{22}$.

\section{Referencias}

Esteban, E. (2015) “Antonio Rodríguez Huéscar y José Ortega y Gasset: tres cartas” en Bajo palabra. Revista de Filosofía, 2015, época II n 11: 19-39.

19 Me he ocupado a fondo de esta cuestión en (Lasaga: 2011 y 2015). Muy resumida, la cuestión reside en que la izquierda cultural compró, sin revisar ni criticar, los lugares comunes que sobre Ortega y sus discípulos había elaborado el nacional-catolicismo.

20 Huéscar mantenía el mismo juicio que había formulado en la "Carta abierta a José Antonio Maravall en el decenario de la muerte de Ortega en 1965, aparecido en Cuadernos Hispanoamericanos.

21 Rodríguez Huéscar 1994 y 1996.

22 La correspondencia que sirvió como inspiración al mencionado curso fue publicada póstumamente en “Correspondencia Ferrater Mora - Antonio Rodríguez Huéscar” (1993). 
Ferrater Mora - Rodríguez Huéscar, (1993), Boletín de la Institución Libre de Enseñanza, Madrid, $\mathrm{n}^{\circ}$ 16: 7-34, y n ${ }^{\circ}$ 17: 7-32, 1993. (Edición de J. Lasaga).

Fusi, J.P., (2017), Espacios de libertad. (La cultura española bajo el franquismo y la reinvención de la democracia, 1960-1990). Barcelona: Galaxia Gutemberg.

Gaos, J., (1999) Obras completas, Epistolario y papeles privados, vol. XIX, México: Universidad Nacional Autónoma de México.

González Álvarez, A. (1955) "El pensamiento de Ortega y el futuro de la filosofía”, en Acto en memoria del catedrático José Ortega y Gasset, Madrid: Universidad de Madrid.

Juliá, S., (2004), Historias de las dos Españas, Madrid: Taurus.

Laín, P. (1955), Acto en memoria del catedrático José Ortega y Gasset, Madrid: Universidad de Madrid.

Lasaga, J., (2011) “Antonio Rodríguez Huéscar: el momento 'escolar' de una filosofía”, Calanda, Boletín de estudios de filosofía y cultura Manuel Mindán, VI, 107-120

Lasaga, J., (2013), "La invención del orteguismo", en Circunstancia, Revista electrónica de la Fundación Ortega-Marañón, Madrid, n 30, enero

Maravall, A., (1959) Ortega en nuestra situación, Madrid: Taurus.

Mindán, M., (2001), "El magisterio de José Gaos en España”, en Teresa Rodríguez de Lecea (ed.), En torno a José Gaos, Valencia: Intitució Alfons el Magnanim.

Muguerza, J. (2004), "Semblanza de Antonio Rodríguez Huéscar”, Prólogo a La innovación metafísica de Ortega. Crítica y superación del idealismo, Madrid, Biblioteca Nueva.

Ortega y Gasset, J., (2004-2010) Obras completas, Madrid: Taurus-Fundación José Ortega y Gasset.

Padilla J. (2004), Antonio Rodríguez Huéscar o la apropiación de una filosofía, Madrid: Biblioteca Nueva - Fundación José Ortega y Gasset

Rodríguez Huéscar, A. (1964), Con Ortega y otros escritos, Madrid: Taurus.

Rodríguez Huéscar, A. (1964), "Sobre el origen de la actitud teorética" en Con Ortega y otros escritos, 93-114.

Rodríguez Huéscar, A., (1994), Semblanza de Ortega, Ciudad Real: Anthropos-Diputación de Ciudad Real. (Edición de J. Lasaga).

Rodríguez Huéscar, A., (1996), Éthos y lógos Madrid: Universidad Nacional de Educación a Distancia. (Edición de J. Lasaga).

Rodríguez, Eva, (2015), “Testimonio: “Cuando Antonio Rodríguez Huéscar, mi padre...” en Bajo palabra. Revista de Filosofía, época II n ${ }^{\circ} 11,37-39$.

Unamuno, M., (2005) Del sentimiento trágico de la vida, Madrid: Tecnos. 
